\title{
UMA HISTÓRIA DA IDADE MÉDIA ATRAVÉS DO CORPO
}

\section{A HISTORY OF THE MIDDLE AGES THROUGH THE BODY}

Bruno Silva de Souza*

LE GOFF, Jacques; TRUONG, Nicolas. Uma história do corpo na Idade Média. Tradução de Marcos Flamínio Peres. 2 ed. Rio de Janeiro: Civilização Brasileira, 2010. 207 p.

O livro de Jacques Le Goff e Nicolas Truong é sobre a história do corpo na Idade Média; informa-o o próprio título. Todavia, podemos tomá-lo sob uma ótica mais ampla: trata-se de uma história da Idade Média através do corpo. Tal afirmação, longe de constituir mero jogo linguístico, atenta para a potencialidade de se tomar o corpo - e a forma como o homem se relaciona com ele - enquanto fonte de grande valor para a investigação histórica. Neste sentido, Uma história do corpo na Idade Média, além compor um capítulo importante desse projeto de se estudar a história do corpo ${ }^{1}$, oferece ao leitor interessado na história da Idade Média no ocidente uma narrativa cujo ponto de partida é aquilo que de mais concreto há na história do homem: seu corpo. Essa história do corpo é, ainda, parte integrante e fundamental da história das mentalidades, tema caro aos historiadores franceses vinculados ao legado dos Annales, tal como o próprio Jacques Le Goff.

Evidentemente, essa percepção em relação ao corpo enquanto objeto da história é ainda relativamente recente no campo dos historiadores, embora haja (e os próprios autores chamam atenção para esse fato) algumas exceções que mencionaremos mais adiante. Surge, então, uma questão interessante: como o corpo pôde ser, durante tanto tempo, marginalizado pela pesquisa histórica? Ocorre que na divisão natureza/cultura o corpo foi tradicionalmente

\footnotetext{
* Mestre pelo Programa de Pós-Graduação em História da Universidade Federal Rural do
} Rio de Janeiro (UFFRJ). E-mail: brunohistrural@yahoo.com.br 
encarado como algo que pertencesse ao primeiro domínio. ${ }^{2}$ Razão pela qual a advertência de Marc Bloch é tão significativa: "Aprendemos que o homem também mudou muito: em seu espírito e, sem dúvida, até nos mais delicados mecanismos de seu corpo". ${ }^{3}$ Essas palavras constituem uma observação que, de forma alguma, poderia ser da ordem da evidência. Os autores do livro que ora apresentamos tiveram o cuidado de passar em revista geral, na introdução à obra, o percurso da entrada do corpo na história. Comecemos, pois, por aqui.

As exceções ao silêncio persistente sobre a história do corpo encontram, como ponto de partida sugerido pelos autores, os trabalhos de Michelet: $O$ povo (1377) e A feiticeira (1862). Michelet forneceu, nos dois trabalhos citados, um exemplo do que os autores chamam de "método histórico encarnado", cuja proposta seria a de "ressuscitar os corpos dos homens do passado, mas também a intuição da importância do corpo através das eras". ${ }^{4}$ Todavia, reconhecem, foi necessário aguardar um mergulho efetivo da história nas ciências sociais para que o corpo pudesse aparecer como objeto da pesquisa histórica. Neste sentido, os autores apontam as influências principais advindas de cientistas sociais: notadamente Marcel Mauss e Norbert Elias: o primeiro dos quais, sendo o pioneiro no interesse pelas "técnicas do corpo", demonstrando como a lógica de utilização dos corpos podia variar (e variava) em função das diferentes sociedades, da moda, da busca pelo prestígio, das educações, das conveniências, da influência do cinema, etc. ${ }^{5}$ Elias, por sua vez, destacou-se por aplicar a lógica da sociologia e antropologia na explicação histórico-sociológica da formação da civilização no ocidente, cujo debate, de tão familiar, talvez nos dispense de maiores considerações.

À lista de contribuições, os autores acrescentam o nome de Johan Huizinga e seu Outono da Idade Média, de 1919 (portanto vinte anos antes da publicação de $O$ processo civilizador de Elias). Mas será com a contribuição de Marc Bloch e Lucien Febvre que a "instituição histórica" se beneficiará de "uma verdadeira atenção" e transformará a questão em um "verdadeiro programa de pesquisa". ${ }^{6}$ A partir de então, os estudiosos de variadas áreas voltaram, com interesse crescente, seus estudos para as questões do corpo: Adorno, Horkheimer, Kantorowicz, Peter Brown, Paul Veyne, Bakhtin e, para não nos estendermos demasiado, Michel Foucault, cuja importância é tão bem avaliada por esse texto introdutório do livro de Le Goff e Truong.

É hora de nos perguntarmos qual será a tônica de Uma história do corpo na Idade Média. Qual a tese fundamental do livro? O que se procura demonstrar? Não é tarefa complicada responder a estes questionamentos, dada a clareza com que os autores expõem a questão: o corpo é atravessado, durante toda a Idade Média, por uma tensão e um paradoxo. O paradoxo consiste no duplo posicionamento do cristianismo em relação ao corpo. Por um lado, "o corpo é desprezado, condenado, humilhado"; por outro lado, "o corpo é 
glorificado no cristianismo medieval". ${ }^{7}$ Se o corpo foi o grande perdedor do pecado original à luz da interpretação teológica medieval, ele foi, também, reabilitado não só pela encarnação de Cristo, como pela sua ressurreição em carne. Da mesma forma, a liturgia da eucaristia dá lugar ao sangue e ao corpo de Cristo. Prova dessa valorização do corpo de Cristo encontra-se na fortuna encontrada pela metáfora paulina do corpo místico. ${ }^{8}$

A tensão, por sua vez, refere-se aquilo que os autores caracterizam como uma "dinâmica do Ocidente": a quaresma e o carnaval. O corpo é atraído ora para o jejum, ora para a gula; ora para a renúncia, ora para o prazer. É nesta oposição entre quaresma e carnaval, que os autores foram buscar em Mikhail Bakhtin", que a vida cotidiana medieval oscila. Tal oscilação, afirmam, "tem a ver, provavelmente, com o lugar central que o corpo ocupa no imaginário e na realidade da Idade Média". ${ }^{10}$

Uma história do copo na Idade Média divide-se em quatro partes: 1) Quaresma e Carnaval: uma dinâmica do Ocidente, 2) Viver e morrer na Idade Média, 3) Civilizar o corpo, 4) O corpo como metáfora. A primeira parte aborda questões referentes às práticas de subjugação do corpo, aos domínios da sexualidade, dos tabus a ela associados e sua repressão e codificação pela igreja. Mas a recusa do corpo, para além da sexualidade e do sofrimento, marcava-se também no domínio da alimentação, onde o gordo e o magro ofereciam a materialização corporal da oposição quaresma-carnaval. Também o trabalho é objeto de discussão. Trata-se de abordar a própria tensão entre o trabalho enquanto penitência (sobretudo na Alta Idade Média - séculos V-XI) e o trabalho enquanto atividade provida de alguma nobreza, sobretudo entre os séculos XI e XIII, quando se observa o que os autores chamam de "uma revolução mental", capaz de valorizar o trabalho, até então predominantemente evocado como signo do pecado original e do declínio humano. ${ }^{11}$ Por fim, o choro, o riso e o sonho. Aqui os autores abordarão, sobretudo, as interpretações concernentes a cada uma dessas manifestações do corpo, que foram objeto de especial atenção na Idade Média, demonstrando como os dois primeiros foram associados ao divino e ao diabólico, respectivamente, e como o sonho foi ora associado às manifestações malignas, ora reabilitado pela leitura do antigo testamento, "onde se sonha muito mais do que no Novo". ${ }^{2}$ Mas os autores advertem que essas associações pretendidas pela igreja estavam sujeitas às variações que, por vezes, partiam dos próprios teólogos. E, não raro, tais manifestações passavam de diabólicas a divinas, e vice e versa.

A segunda parte do livro investiga o estado dos saberes médicos no medievo, a expectativa de vida do período e os estragos trazidos com a peste negra, que dizimou, em quatro anos (1347-1352), um quarto da população ocidental. ${ }^{13}$ Trata-se, também, das divisões da vida pelas quatro idades (criança, jovem, adulto e velho) e da correspondência de cada uma dessas idades com 
os quatro humores descritos na medicina hipocrática: sangue, bile, pituíta e atrabílis. Outro ponto de destaque são as doenças, e os autores discutem em especial o estigma da lepra, associada ao pecado e à concepção em períodos restritos pela igreja (Quaresma, dias santos, etc.). Por fim, os mortos ocupam um lugar na história medieval. Le Goff e Truong analisam o imaginário medieval acerca da morte e o espaço que aquela sociedade lhe dedicava.

$\mathrm{Na}$ terceira parte do livro, os autores concentram-se na empresa de civilização do corpo, levada a cabo pela igreja, que não pôde, efetivamente, controlá-lo por inteiro. ${ }^{14} \mathrm{~A}$ exposição do corpo nu, a codificação dos gestos, da alimentação, dos modos em geral. Trata-se de um capítulo estreitamente relacionado ao clássico trabalho de Norbert Elias: O processo civilizador, volume 1. Um estudo, portanto, dos costumes mais cotidianos, mas de maneira alguma naturais.

A última parte reflete sobre a utilização metafórica do corpo, a associação da república com o corpo e seus membros (e suas funções), resultado direto da associação paulina da igreja com o corpo e do Cristo como cabeça. De raízes gregas e romanas (antigas, portanto), a associação metafórica da república com o corpo irá se assentar na Idade Média. ${ }^{15}$ Aqui se definirão usos e analogias que informarão, inclusive, o pensamento político nos séculos XVI e XVII. ${ }^{16}$ Afirma-se uma visão organicista do mundo político (em seu sentido amplo) que marcará presença por muito tempo.

É muito a propósito que o livro termine com uma alusão à "história lenta", uma vez que, conforme se afirma, o corpo alimenta a história das mentalidades, lenta por definição. Não obstante os acontecimentos abruptos, como a peste negra no medievo e a corrida médico-estética dos séculos XX e XXI, o corpo mexe-se sem pressa no que tange ao essencial. Descreve uma lenta trajetória. Deixa sua história pelo caminho. Ajuda a pintar um quadro algo mais colorido da Idade Média, fazendo rejeitar - projeto que percorre praticamente toda a produção de Le Goff - a clássica associação do período a uma Idade das Trevas.

\section{NOTAS}

1 Destaque-se, nesse campo, a importância de Alain Corbin, Geroges Vigarello e Jean Jacques Courtine: CORBIN, Alain; VIGARELLO, Georges; COURTINE, Jean-Jacques (Orgs.). História do corpo. Petrópolis: Vozes, 2008. 3 v.

2 LE GOFF, Jacques; TRUONG, Nicolas. Uma história do corpo na Idade Média. Tradução de Marcos Flamínio Peres. 2 ed. Rio de Janeiro: Civilização Brasileira, 2010. p. 16.

3 BLOCH, Marc. Apologia da História ou o ofício de historiador. Rio de Janeiro: Jorge Zahar Editor, 2002. p. 65. 
${ }^{4}$ LE GOFF; TRUONG, op. cit., p. 16.

${ }^{5}$ Idem, p. 18-19.

${ }^{6}$ Idem, p. 22.

${ }^{7}$ LE GOFF; TRUONG, op. cit., p. 11-12.

${ }^{8}$ Aqui cabem algumas considerações a respeito da terminologia. Ocorre que, apesar do parentesco com as ideias do apóstolo Paulo, a expressão corpus mysticum fora cunhada muitos séculos depois. De fato, o apóstolo apresentara o conceito de igreja como corpus Christi, isto é, o corpo de Cristo. Segundo nos informa Ernst Kantorowicz, a expressão corpus mysticum ganhou proeminência na época carolíngia, associada à controvérsia da Eucaristia e, por transferência, qualquer corpo político. A metáfora de são Paulo é encontrada, entre outras passagens, em 1Cor 6,$15 ; 12,12.27$; Ef 4, 4.16.25 e 5, 30. (o primeiro número após a abreviatura do nome indica o capítulo, ao passo que os números seguintes indicam os versículos). Cf. KANTOROWICZ, Ernst H. Os dois corpos do rei: um estudo sobre teologia política medieval. Tradução de Cid Knipel Moreira. São Paulo: Cia das Letras, 1998. p. 127-133.

9 Le Goff e Truong apontam a obra A cultura popular na Idade Média e no Renascimento: o contexto de François Rabelais, publicada em 1970, como o trabalho orientador sobre a questão dessa oposição entre quaresma e carnaval (p. 27-28).

${ }^{10}$ LE GOFF; TRUONG, op. cit., p 35.

${ }^{11}$ Idem, p. 67.

${ }^{12}$ Idem, p. 83.

${ }^{13}$ Idem, p. 105.

${ }^{14}$ Idem, p. 133.

${ }^{15}$ Idem, p. 155.

${ }^{16}$ Remeto ao livro de Michel Senellart: SENELLART, Michel. As artes de governar: do regimen medieval ao conceito de governo. Tradução de Paulo Neves. São Paulo: Ed. 34, 2006.

Resenha recebida em dezembro de 2011. Aceita em março de 2012. 